\title{
CYTOKINE AND ACUTE PHASE RESPONSE IN CALVES FOLLOWING EXPERIMENTAL INFECTION WITH BRSV
}

\author{
${ }^{1}$ Grell, S.N., ${ }^{2}$ Tjørnehøj, K., ${ }^{1}$ Larsen,L.E., and ${ }^{1}$ Heegaard, P. \\ ${ }^{1}$ Danish Veterinary Laboratory, Bulowsvej 27, DK 1790 Copenhagen, Denmark \\ ${ }^{2}$ Danish Veterinary Institute for Virus Research, Lindholm, Denmark.
}

Bovine respiratory syncytial virus has been identified as an important pathogen associated with acute respiratory disease in calves. An infection model has been developed reflecting the clinical course and the development of pathological signs during a natural BRSV-infection. Calves were infected at age 15-20 weeks and reinfected 14 weeks later. Clinical signs and virus excretion were monitored daily. Blood samples were obtained in the whole period and investigated for the acute phase proteins: haptoglobin and serum amyloid A (SAA) and for the cytokines: interleukin-2 (IL-2), interleukin-4 (IL-4), interleukin-6 (IL-6) and interferon-gamma (IFN().

Haptoglobin and SAA were measured by ELISA and cytokine expression (mRNA) were determined by a quantitative real time RT-PCR (Taq-Man technology).

The results showed an induction of IL-6, haptoglobin, SAA and IFN $\gamma$, to the first experimental infection, whereas there was a smaller induction of IFN $\gamma$, and no induction of IL-6, haptoglobin and SAA in the reinfection. Indication of a correlation was found between IL-6 expression and clinical signs and also acute phase protein induction and clinical signs. Another correlation was found between IFN $\gamma$ and virus excretion.

In conclusion, it seems that early mediators are important for the clinical outcome of infection, and that cytokines and acute phase proteins can be useful as clinical parameters reflecting the establishment, development and severity of the infection.

\section{EVALUATION OF LEVAMISOLE ADMINISTRATION AT DRY PERIOD FOR CONTROLLING POSTPARTUM BOVINE MASTITIS}

\author{
N. Farzaneh, M.Rad, M.Mohri, J.Saadati \\ Department of Clinical Sciences, School of Veterinary Medicine, Ferdowsi University of Mashhad, Mashhad, \\ P.O.Box: 91775-1793, Iran
}

Levamisole is an antihelmintic drug, which also has immunomodulatory effects.Levamisole has influenced host defense by modulating cell-mediated immune response, humoral immunity response and enhancement of macrophage and polymorphonuclear cell function. Levamisole modulates immune function at 2 to $3 \mathrm{mg} / \mathrm{kg}$ bodyweight. Several researches have been performed to evaluate these immunomodulatory effects of levamisole for prevention and treatment of bovine mastitis, but results of these studies have been conflicting. The aim of this study was to evaluate the effects of the drug on the prevention and treatment of mastitis at the dry period. Ninety- four Holstein cows at dry pe- 
riod of a dairy herd were selected randomly. Levamisole was administrated orally to 46 cows (test group) at a dose of $2.5 \mathrm{mg} / \mathrm{kg}$ at 3 days interval, during the first 45 days of dry period. Forty- eight cows were chosen as control group. The cows were paired according to parity and milk yield. All cows received a dry cow mastitis ointment ${ }^{1}$ at drying off. The treatment was ceased approximately 2 weeks before expected time of parturition. Each cow received 16 treatments on average.Stool exam was also performed on both the test and control groups.Bacteriological assessment was performed on milk at drying off (before administration of dry cow mastitis ointment) and postpartum days: 5 , 15 and 25.The cows were clinically examined and the udders were inspected for signs of inflammation, induration and swelling. The milk was also checked for changes in the consistency.The results of this study showed that the incidence of new mastitis cases were significantly different $(p<0.05)$ between the test and control groups (29.3\% vs. $45.8 \%$, respectively). Positive response to treatment of existing intramammary infections was not significantly different between the two groups. The incidence of new mastitis cases were also significantly different $(\mathrm{p}<0.05)$ between the test and control groups according to parity (2nd to 4 th parity cows) ( $26 \%$ vs. $56 \%$, respectively) and milk yield (intermediate milk yielding cows) $(26.3 \%$ vs. $58.8 \%$, respectively). On behalf of these results it seems that levamisole had no effects on treatment of mastitis cases. Theoretically, levamisole can have only a limited beneficial effect in the treatment of mastitis because the magnitude of the neutrophil response is not a limiting factor in the defence of the mammary gland against bacteria and therefore any enhancement of neutrophil chemotaxis by levamisole is unlikely to be of value. The results of this study showed that levamisole exerts its effects through prevention of new mastits cases ( prevention of the development of disease once organisms have entered the mammary gland).

Anderson, J.C. Levamisole and bovine mastitis. Veterinary Record(1984) 114,138-140

${ }^{1}$ Albadry Plus- UpJohn Company, Belgium

\title{
ON BCS EVALUATION IN ESTONIAN HEIFERS AND PRIMIPAROUS COWS
}

\author{
Katri Ling ${ }^{1}$, Jaak Samarütel ${ }^{1}$, Andres Waldmann², Toomas Tiirats ${ }^{2}$ \\ ${ }^{1}$ Institute of Animal Science, Estonian Agricultural University, Kreutzwaldi 1, 51014 Tartu, Estonia \\ ${ }^{2}$ Faculty of Veterinary Medicine, Estonian Agricultural University, Kreutzwaldi 62, 51014 Tartu, Estonia
}

To introduce body condition scoring (BCS) in Estonia, repeatability of the scoring of Estonian breeds was evaluated and the relationship of BCS change with body weight $(\mathrm{BW})$ change of primiparous cows was analysed.

Every fortnight 40 Estonian Holstein, 24 Estonian Red, 20 Red Holstein and 4 Estonian Native breed heifers and primiparous cows on an experimental farm were scored during 10 weeks on a five-point scale outlined by Wildman et al (1982). Every time all animals obtained two scores: one from an evaluator who used Edmondson's evaluating chart and the other from a pair of evaluators using Ferguson's decision chart for BCS. The observers had previous independent experience. Observers 
agreed $(r=0,88)$ with the absolute score in $37.7 \%$ of the cases, deviating by 0.25 units in $45.3 \%$ of the cases. The best coincidence of the scores was between the values from 2.0 to 3.5 points. Our results confirmed the reliability of the method. To better standardise the scoring a single evaluation system must be used. We preferred Ferguson's method because of its step by step build-up.

Every fortnight 42 Estonian Holstein and 24 Estonian Red pregnant heifers and primiparous cows were BC scored (Edmondson's chart) starting from 2 weeks before calving and weighed on a scale once a month from calving to 20 weeks post-partum. Regression analysis showed significant $(\mathrm{P}<0.01)$ correlation between BW change and BCS change during the period of postparturient BCS decline of 12 weeks in Estonian Holstein (from 3.7 to 2.7) and 14 weeks in Estonian Red cows (from 3.9 to 3.1). According to our preliminary data, $1 \mathrm{BCS}$ point change corresponded to $72 \mathrm{~kg}$ change in Estonian Holstein and $52 \mathrm{~kg}$ in Estonian Red primiparous postparturient cows. In both breeds $1 \mathrm{BCS}$ point change corresponded to $13 \%$ of BW change.

1. Edmondson A.J., Lean I.J. Weaver L.D. Farver T. Webster G., 1989.A body condition scoring chart for Holstein dairy cows. J. Dairy Sci.72: 68.

2. Ferguson J. D., David T., Galligan,T., Thomsen N., 1994. Principal descriptors of body condition score in Holstein cows. J. Dairy Sci. 77:2695.

3. Wildman,E.E., Jones, G.M., Wagner, P.E., Boman, R.L., Troutt, H.F., Lesch, T.N, 1982. A dairy cow body condition scoring system and its relationship to selected production characteristics. J. Dairy Sci. 65: 495.

\title{
EFFECTS OF DIFFERENT REARING METHODS ON HEALTH STATUS, IMMUNITY AND PERFORMANCE OF ARTIFICIALLY REARED CALVES
}

\author{
Bernadette Earley
}

Teagasc, Grange Research Centre, Dunsany, Co. Meath, Ireland.

Morbidity and mortality of the young calf represent a major cause of economic concern for producers (Earley et al., 1997). The objective of the study was to evaluate the performance and immune status of calves reared in the presence or absence of quartz linear heating lamps (CD 3000) and fed calf milk replacer either by bucket or by teat. Mart-purchased Holstein/Friesian calves were approximately 21 days of age at arrival at the research centre. The calves were allocated randomly to one of the following four treatments ( $\mathrm{n}=16$ calves per treatment) using a 2 × 2 factorial design; 1$)$. Teat fed + quartz linear lamp (QLL) (2). Bucket fed + QLL; 3). Teat fed + no QLL and 4). Bucket fed + no QLL. For the 42-day experimental period, 8 groups of 8 calves were penned $(2.4 \times 10.0 \mathrm{~m})$ on straw in a naturally ventilated Monopitch calf house. A quartz linear heating lamp (3 k output) was positioned in the centre of the individual sheds, 10 feet above the floor of the straw bedded pens for these on QLL treatments, and remained switched on for the duration of the study. The calves received an individual allowance of $25 \mathrm{~kg}$ of milk replacer powder offered warm $\left(38^{\circ} \mathrm{C}\right)$ by bucket and had $\mathrm{ad} \mathrm{li-}$ bitum access to a concentrate ration. Individual disease episodes were determined by the requirement to treat with antibiotics for either enteric disease or respiratory disease. Serum immunoglobulins $\left(\mathrm{IgG}_{1}\right)$ were measured quantitatively by single radial immunodiffusion standard and calculated via 
an internal Ig standard (100 mg/L) on days 1, 14 and 28 of the study. Haematological parameters were measured on days 1, 14 and 42 of the study and included red blood cell number, haemoglobin, packed cell volume, mean cell volume and total white cell counts. The data were analysed using a model appropriate to factorial design, with terms for QLL and teat in the main plot. The average temperature and relative humidity of the shed compartments with and without the QLL heating lamps were recorded continuously and were $11.3^{\circ} \mathrm{C}$ and $81 \%$ and $10.5^{\circ} \mathrm{C}$ and $86 \%$, respectively. There was no significant difference $(\mathrm{P}>0.05)$ between treatments with respect to liveweight gain from day of arrival (day 1) to day 42 of the study. There was no significant interaction between QLL, no QLL, teat fed and bucket fed treatments with respect to serum IgG1 concentrations and haematological parameters throughout the study period $(\mathrm{P}>0.05)$. The incidence of respiratory disease and enteric disease was similar across the treatment groups $(\mathrm{P}>0.05)$. It is concluded that the rearing of calves indoors, in the presence of quartz linear heating lamps, and either fed calf milk replacer by teat or bucket had no beneficial effect on calf health and performance when compared with calves reared in a natural ventilated environment.

\title{
References
}

Earley, B., Fallon, R.J. \& Drennan, M.J. (1997). (Abstract). Ir. Jr. Agri. Fd. Res. 36:1, 124.

\section{BACILLUS CEREUS FROM THE FOOD OF ANIMAL ORIGIN IN INDIA AND ITS PUBLIC HEALTH SIGNIFICANCE}

\author{
Sharma C S, Sharma D K, Gill J P S, Aulakh R S and Sharma J K \\ Department of Veterinary Public Health Punjab Agricultural University \\ Ludhiana-141004, INDIA \\ Phone: +91-161-401960 Ext. 444. FAX: +91-161-400822. Email: shekhar_76@123india.com
}

\section{Objectives}

1.Isolation and enumeration of Bacillus cereus from different food samples and outbreaks if any. 2.Characterization of the isolates. 3.Extraction and detection of enterotoxins from the isolates and their correlation with public health.

\section{Methods}

172 samples viz. milk (27), milk products (38), meat (39), meat products (32) and swab samples (36) procured from local market in and around Ludhiana city (India) were screened for isolation of $B$. cereus.

\section{Results}

The per cent isolation of $B$. cereus from milk, burf, milk powder, chicken, mutton, butter chicken, mutton soup, chicken soup and swab samples were 66.6, 44.8, 44.4, 63.2, 55.0, 57.9, 33.3, 57.1 and 16.7 , respectively resulting an overall incidence of 47.1 per cent. Maximum isolation of $B$. cereus 
could be made from milk (66.6\%) followed by chicken (63.2\%). None of the swab samples from butcher's knives was found to contain B. cereus. Bacterial load of B. cereus organism in 17.3 per cent of positive samples was more than $10^{5}$ c.f.u./g, which is beyond safe, acceptable limits in food meant for human consumption. The isolates were got confirmed, typed and biotyped from PHLS laboratory, Colindale, London (U.K.). Different Bacillus spp. (other than B. cereus) isolated was B. subtilis (12.2\%), B. licheniformis (5.2\%), B. mycoides (9.6\%) and B. thurigensis (1.7\%).

\title{
Conclusions
}

A total of 38.3 per cent of B. cereus isolates were found to be enterotoxigenic as detected by rabbit ileal loop method and rabbit skin vasopermeability factor test. A positive correlation has been observed between two methods. Public health significance of these findings will be discussed.

\section{NEMATICIDAL EFFECT OF BACILLUS THURINGIENSIS ON TRICHOSTRONGYLUS COLUBRIFORMIS INFESTING RABBITS}

\author{
M.A. Hassanain, M.M. Abd El aziz, N.M Abou el ezz \\ National Research Center - Dokki - Giza- EGYPT.
}

The field of biological control has been recently established in many countries trying to minimize the hazards of insecticides and chemicals and to help for environmental and human protection. The present study was directed towards the use of non- harmful non- pathogenic bacteria, bacillus thuringiensis (B.T) as nematicide towards Trichostrongylus colubriformis in rabbits.

Eggs and larvae of adult nematode worms, T. colubriformis were obtained and exposed to six dilutions of B.T. Kurstaki $0.3,0.6,1,1.5,2$ and $2.5 \mathrm{mg}$ and toxin. The biologically treated eggs and larvae were incubated at $28^{\circ} \mathrm{C}$ and examined for development, activity and motility. The ovicidal and larvicidal activity of B.T. Kurstaki and its toxin were recorded. Also anthelmintic activity of B.T. Kurstaki against $T$. colubriformis infection in rabbits were evaluated by s/c injection of infected rabbits with a dose of $5 \mathrm{mg} / \mathrm{kg}$ body weight. Both treated infected rabbits and control ones were sacrified after 2 weeks post treatment and the intestine was prepared for worm detection. The data were subjected to statistical analyis based on the work of Polo- Pc (Robertson et. al. 1980) to determine LD50 values.

The ovicidal and larvicidal activities were higher with prolonged exposure of parasitic eggs and larvae to bacteria and its toxins. The ovicidal activity of bacteria and toxin were increased to be $93.71 \%$ and $93.66 \%$ respectively at $2.5 \mathrm{mg}$ concentration. The larvicidal effects of bacteria reached to $100 \%$ and $98 \%$ for bacteria and toxin respectively at $2 \mathrm{mg}$. Also the anthelmintic activity of B.T. kurstaki against $T$. colubriformis in rabbits showed a daily gradual decrease in number of eggs/ gm. Feces and disappearances of eggs after 10 days post treatment. Also the intestines of sacrificed infected rabbits were free from adult nematode. The study revealed the successful biological treatment of infected rabbits with T.colubriformis by non- harmful bacteria, B.T. kurstaki

This work was supported by the national research center, Egypt (Biological control research project: 3-1-3-2). 